\section{A Facile and}

Completely

Green Route for

Synthesizing Gold

Nanoparticles by

the Use of Drink

\section{Additives}

\section{Chien-Chen Wu and Dong-Hwang Chen}

Department of Chemical Engineering National Cheng Kung University Tainan, Taiwan 701, R.O.C.

Tel: 886-6-2757575 Ext.62680

Fax: 886-6-2344496

Address all correspondence to Dong-Hwang Chen at chendh@mail.ncku.edu.tw

\begin{abstract}
A facile and completely green route to synthesize $\mathrm{Au}$ nanoparticles by mixing the $\mathrm{Au}(\mathrm{III})$ ions-dissolved rice wine and soda at a slightly elevated temperature in the absence of extra protective agents was developed. Rice wine was used as a solvent and a reducing agent. Also, soda not only functioned as a protective agent but also played a role of base catalyst. No extra protective agents are needed. From the analyses of UV/VIS absorption spectra, TEM, and XRD patterns, the formation of Au nanoparticles was recognized. The appropriate $\mathrm{pH}$ and temperature were around 6.5 and $25-55^{\circ} \mathrm{C}$, respectively. The resultant solution was quite stable. No precipitation occurred even after several months. In addition, rice wine and soda are often used as the additives of drinks or foods, and are easily obtained in our daily life. So, it becomes possible that people can easily make the Au nanoparticles at home by the route proposed in this work.
\end{abstract}

\section{Keywords}

Gold; nanoparticles; green chemistry; synthesis

\section{Introduction}

Recently, the green chemistry which aims to reduce or eliminate substances hazardous to human health and the environment in the design, development and implementation of chemical processes and products is becoming more and more important [1-2]. To comply with the 12 principles of green chemistry, many researches tried to avoid or reduce the uses of hazardous chemicals and solvents, such as using natural materials instead of traditional toxic chemicals [1-5].

Au nanoparticles can be widely used in catalytic, chemical sensing, biomedical, and optoelectronic fields due to their size-related chemical, optical and electronic properties [610]. Their preparation, dispersion and properties are always receiving considerable attention [6,11-15]. Generally, in order to improve the stability or tune the functionality, protective agents, ligands or organic solvents were used. However, the use of these additives might become a new issue environmentally and violate the green chemistry principles. Recently, a number of green materials such as oligopeptides, vitamin B2, D-glucose, starch, fruit extracts and other biomolecules have been used to substitute for the environmentally hazardous materials [16-19]. Some of them are not easily obtained, needing further purification or extraction from plants or animals. Also, protective agents are usually necessary for controlling particle size at the nanometer scale. So, it is still necessary to continue developing green processes for the synthesis of Au nanoparticles.

In this paper, we report a facile and completely green route for the synthesis of Au nanoparticles. It is well known that some metal nanoparticles could be reduced by alcohol reduction method [20-21], which was usually conducted by reflux around the boiling point of alcohol with soluble polymers as protective agents. Here, instead of organic solvents and compounds, we use rice wine and soda, which are drink and food additives in our daily life, to synthesize Au nanoparticles with a gentle heat in the absence of extra protective agents.

\section{Experimental}

Hydrogen tetrachloroaurate $\left(\mathrm{HAuCl}_{4} .4 \mathrm{H}_{2} \mathrm{O}\right)$ was purchased from Alfa Aesar (Ward Hill, MA). Rice wine (40\% ethanol) and soda (sodium bicarbonate, $\mathrm{NaHCO}_{3} 98 \%$ ) were obtained from supermarkets. All chemicals were used without further purification. In a typical experiment, hydrogen tetrachloroaurate $(0.5 \mathrm{mM})$ was dissolved in rice wine. Subsequently, an appropriate amount of soda was added to adjust the pH values between 5.5 and 7.0 (i.e., 0.0378 and $0.1512 \mathrm{mg}$ soda $/ \mathrm{ml}$ ) and the solution was heated in the range between 25 and $55^{\circ} \mathrm{C}$. It was found that the solution turned blue within $15 \mathrm{~min}$ and started to turn wine red after $1 \mathrm{~h}$, indicating the formation of Au nanoparticles as illustrated in Fig. 1. The effects of soda amount (or $\mathrm{pH}$ ) and reaction temperature were investigated. 


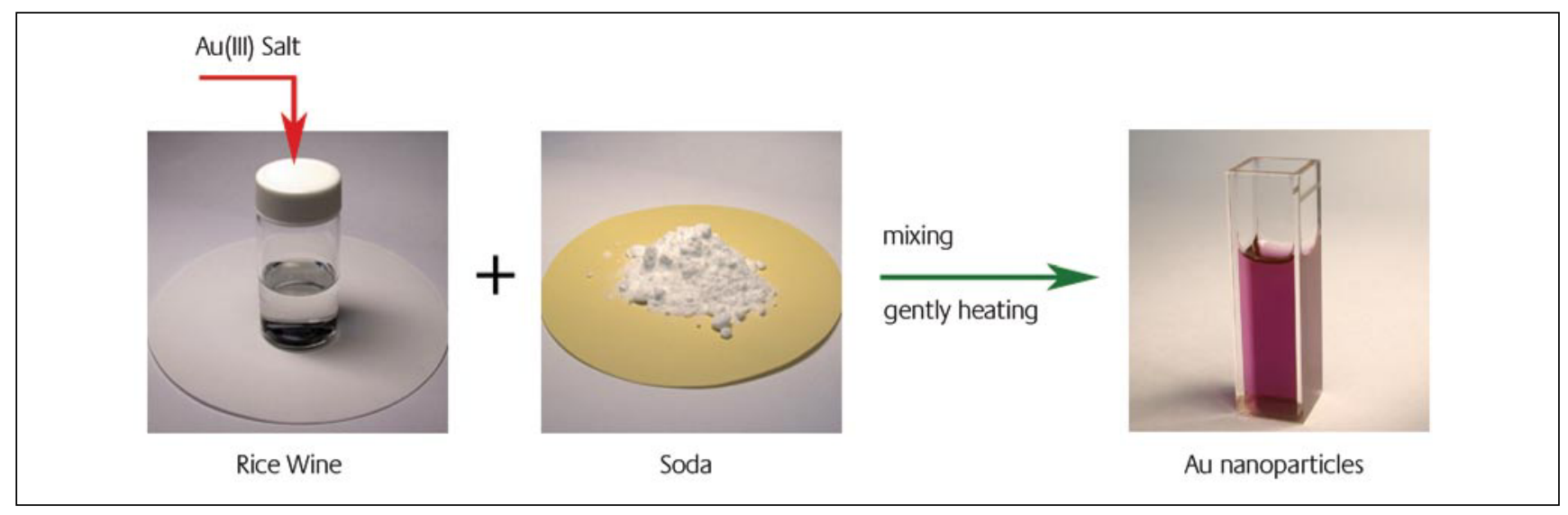

\section{Figure 1}

A scheme for the green synthesis of Au nanoparticles by mixing the Au(III) ions-dissolved rice wine and soda with a gentle heat

The UV-VIS absorption spectra of the resulting colloid dispersion were analyzed by a JASCO model V-570 VU/VIS/ NIR spectrophotometer. The particle size was determined by transmission electron microscope (TEM) using a Hitachi model HF-2000 field emission transmission electron microscope with a resolution of $0.1 \mathrm{~nm}$. The analysis of X-ray diffraction (XRD) pattern was performed on a Shimadzu Model RX-III Xray diffractometer at $40 \mathrm{kV}$ and $30 \mathrm{~mA}$ with CuK $\alpha$ radiation $(\lambda=0.1542 \mathrm{~nm})$ to determine the structure. Fourier transfer infrared (FT-IR) spectrum was recorded on a DIGILAB model FTS 1000 FT-IR Spectrometer.

\section{Results and discussion}

\section{Characteristics of Au nanoparticles}

Fig. 2 indicates the UV-VIS absorption spectra of $\mathrm{Au}$ nanoparticles obtained at $55^{\circ} \mathrm{C}, \mathrm{pH} 6.5$ and various time intervals. The characteristic band of Au nanoparticles occurred at 538-560 nm, instead of $520 \mathrm{~nm}$, and blue-shifted with time. The variation of optical property might be resulted by the larger particle size and nonspherical nanoparticles [2223]. In addition, as shown in the inset of Fig. 2, the intensity

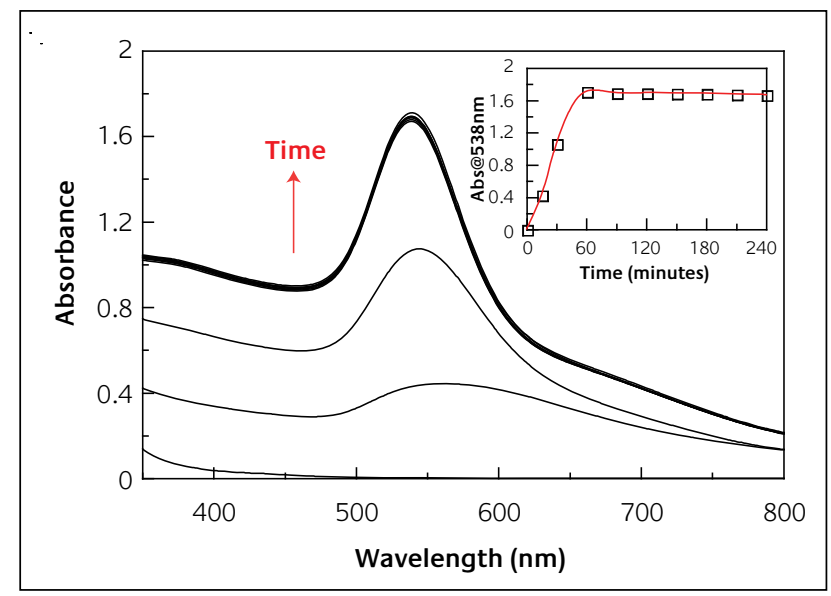

\section{Figure 2}

UV-VIS absorption spectra of Au nanoparticles obtained at $55^{\circ} \mathrm{C}$ and pH 6.5. The inset indicates the time-dependence of the absorbance at $538 \mathrm{~nm}$ at $538 \mathrm{~nm}$ increased with time and reached a constant value after $60 \mathrm{~min}$. This implied the synthesis reaction of Au nanoparticles was finished at this time. In addition, the resultant solution was quite stable. No precipitation occurred due to particle aggregation even after several months. In order to confirm whether the Au(III) ions were completely reduced or not, Au nanoparticles were removed by centrifugation and the supernatant was analyzed using a GBC Avanta atomic absorption spectrometer. It was found no residual $A u(I I)$ ions were detected, revealing the $A u(I I)$ ions have been completely reduced to Au atoms.

The typical TEM image of Au nanoparticles obtained at $55^{\circ} \mathrm{C}, \mathrm{pH} 6.5$ and a reaction time of $4 \mathrm{~h}$ was shown in Fig. $3(\mathrm{a})$. It is obvious that the resultant Au nanoparticles were discrete with a mean diameter of $35.3 \pm 6.1 \mathrm{~nm}$, even in the absence of extra protective agent. Since the $\mathrm{pK}_{1}$ and $\mathrm{pK}_{2}$ of carbonic acid were 6.4 and 10.3, it was suggested that bicarbonate ions might form the electric double layers on the surface of Au nanoparticles and further protected the Au nanoparticles from aggregation. However, the large size and broad size distribution revealed the protective effect was not strong. In addition, the resultant Au nanoparticles were irregularly polygonal rather than typically spherical. This might account for the deviation of characteristic absorption band from $520 \mathrm{~nm}$ as stated above. Fig. 4 indicates the XRD pattern of Au nanoparticles. Four characteristic peaks at $2 \theta$ $=38.1,44.3,64.5$, and $77.4^{\circ}$ which were corresponding to the (111), (200), (220), and (311) planes revealed the resultant Au nanoparticles were in the face centered cubic (fcc) structure.

\section{Effects of soda amount and reaction temperature}

The addition amount of soda determined the $\mathrm{pH}$ value and ionic environment of reaction solutions and therefore might play an important role in the formation of Au nanoparticles. At $55^{\circ} \mathrm{C}$ and $\mathrm{pH} 5.5$ (0.0378mg soda/ml), a broad characteristic band was observed around 572 nm (as shown in Fig. 5(a)) and its intensity increased gradually with time first and then decreased after 60 min owing to the occurrence of precipitation, as indicated in Fig. 6. The TEM image obtained at $4 \mathrm{~h}$ (Fig. 3(b)) showed the resultant Au nanoparticles 


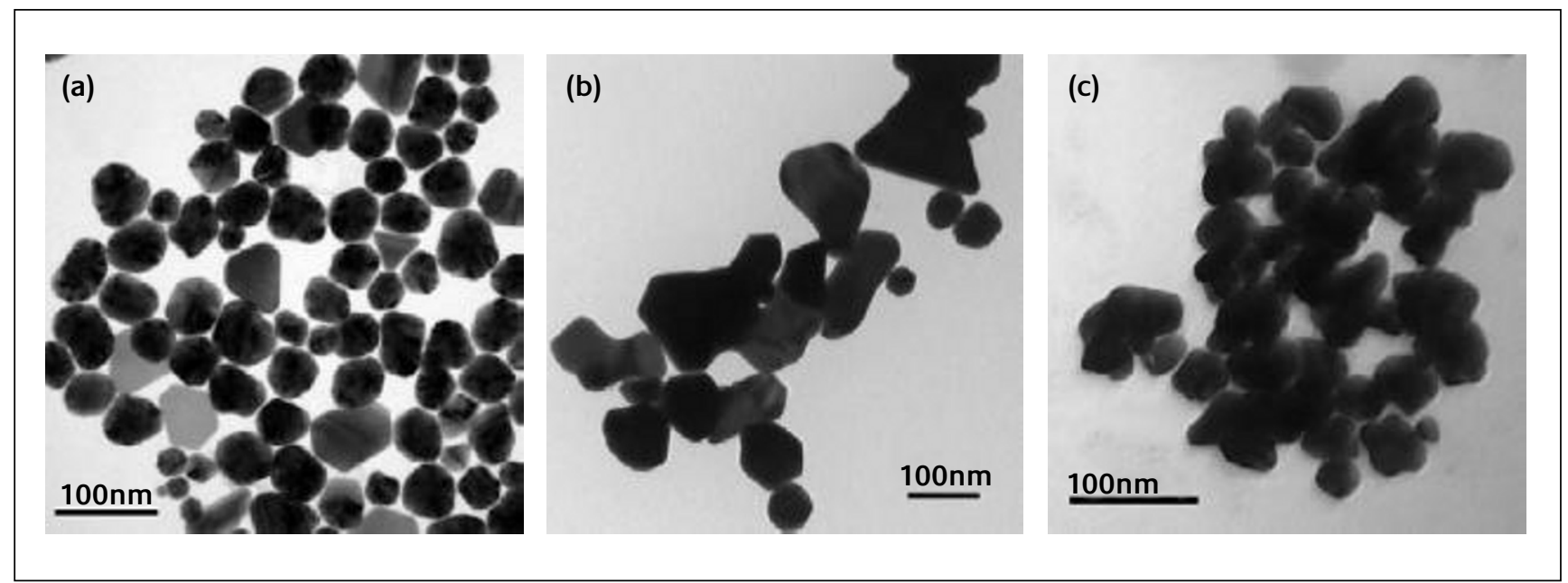

\section{Figure 3}

TEM images of Au nanoparticles obtained at $55^{\circ} \mathrm{C}$ and $\mathrm{pH} 6.5$ (a), 5.5 (b), and 7.0 (c). The reaction time was $4 \mathrm{~h}$ for each case

were irregular in morphology and partially aggregated. This accounted for the broadness and red-shift of characteristic band. It was remembered that the Au nanoparticles obtained at $\mathrm{pH} 6.5$ were discrete and the solution was stable. At $\mathrm{pH}$ 5.5 , most of bicarbonate ions were protonated to carbonic acid molecules. The amount of bicarbonate ions was insufficient for the protection of Au nanoparticles. This explained why the product was partially aggregated and even precipitated.

AtpH 7.0 (0.1512mg soda/ml), a slightly broad characteristic band occurred around 562 nm (as shown in Fig. 5(b)). Its intensity increased rapidly and remained constant after 30 min (Fig. 6), revealing the formation rate was fast and no precipitation occurred. The TEM image obtained at $4 \mathrm{~h}$ (Fig. $3(c))$ revealed the product was partially aggregated like at $\mathrm{pH}$ 5.5, accounting for the slightly broad and red-shifted characteristic band. However, noteworthily, the particle aggregation did not lead to the occurrence of precipitation. In principle, at $\mathrm{pH}$ 7.0, much more bicarbonate ions were present than at $\mathrm{pH}$ 6.5. This should lead to a more effective protection on Au nanoparticles. So, even the product was partially aggregated, no precipitation occurred. Thus, the

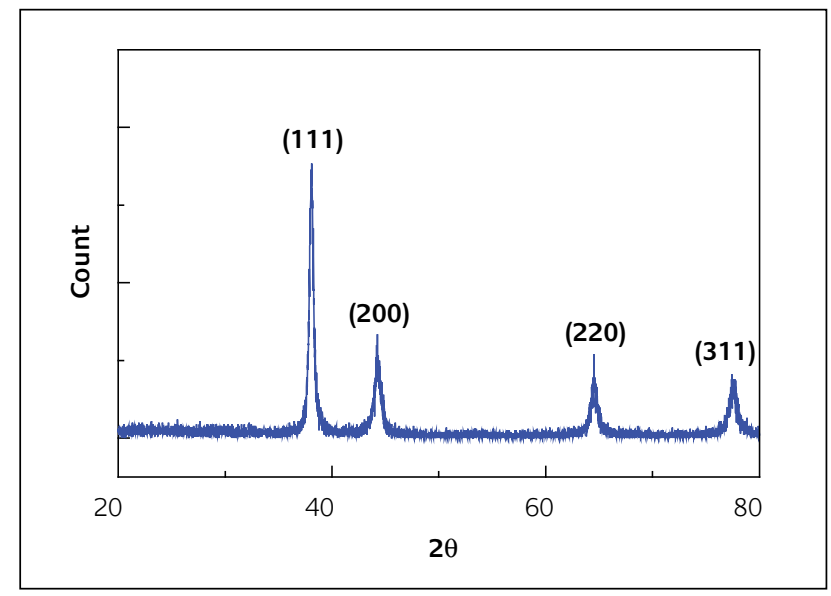

Figure 4

XRD pattern of Au nanoparticles obtained at $55^{\circ} \mathrm{C}$ and $\mathrm{pH}$ 6.5. The reaction time was $4 \mathrm{~h}$ particle aggregation might be resulted by other mechanism. It was suggested that the fast reduction rate of $\mathrm{Au}$ (III) ions at $\mathrm{pH} 7.0$ might lead to the increase in the collision probability of Au atoms, nuclei, and nanoparticles. This might result in the formation of aggregates. When $\mathrm{pH}=8(0.2688 \mathrm{mg}$ soda/ $\mathrm{ml})$, the reaction solution became blue within 1-2 min and

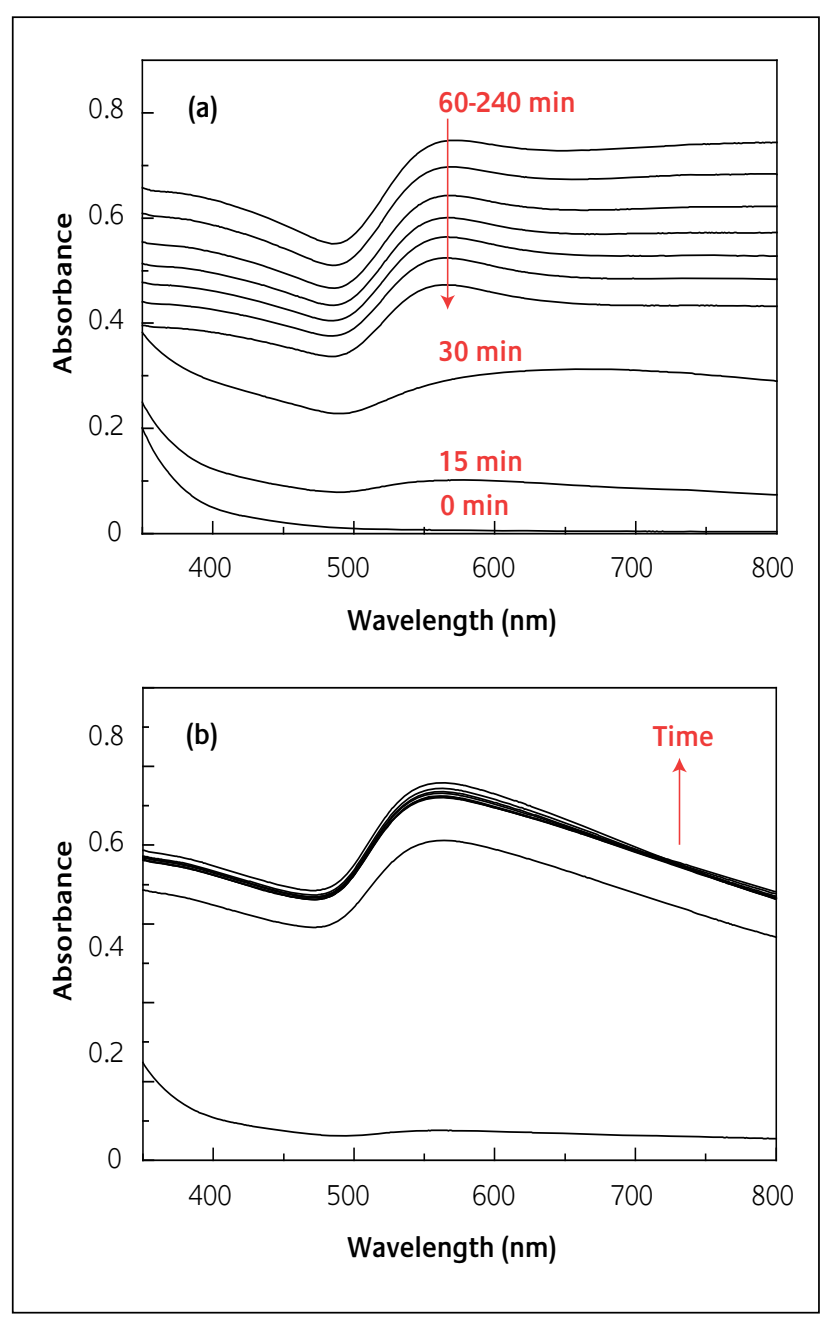

Figure 5

Time-dependent UV-VIS absorption spectra of Au nanoparticles at $55^{\circ} \mathrm{C}$ and pH 5.5 (a) and 7.0 (b) 


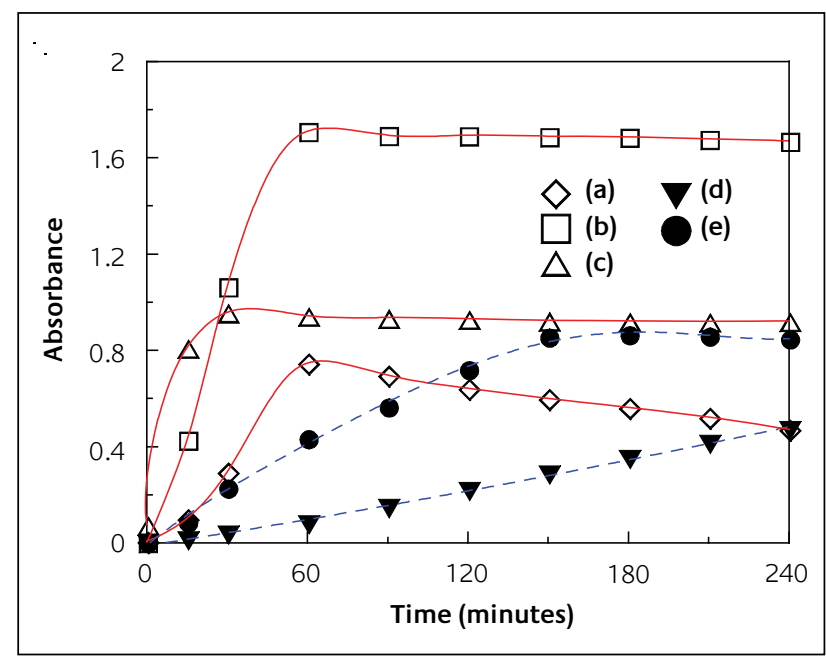

\section{Figure 6}

Time-dependences of the absorbance of Au nanoparticles. Curves (a), (b), and (c) indicate the time-dependences at 572, 538, and $562 \mathrm{~nm}$ for the Au nanoparticles obtained at $55^{\circ} \mathrm{C}$ and pH 5.5 (a), 6.5 (b), and 7.0 (c), respectively. Curves (d) and (e) indicate the time-dependences at 579 and $561 \mathrm{~nm}$ for the Au nanoparticles obtained at pH 6.5 and 25 (d) and $40^{\circ} \mathrm{C}(e)$, respectively

precipitates were observed, revealing the formation rate was quite fast and particle aggregation became more serious. Thus, it was suggested that the synthesis of Au nanoparticles by the route proposed in this work should be performed at $\mathrm{pH}$ 5.5-7.

Temperature is another important factor affecting the formation of Au nanoparticles. At pH 6.5, the characteristic bands shifted to 561 and $579 \mathrm{~nm}$ when temperature decreased to 40 and $25^{\circ} \mathrm{C}$, respectively (as shown in Fig. 7 ), and the formation rate decreased significantly with the decrease in temperature (as indicated in Fig. 6). Furthermore, the corresponding TEM images (also shown in Fig. 7) indicated that particle aggregation occurred significantly even the resultant Au nanoparticles were smaller at $25^{\circ} \mathrm{C}$ due to the incomplete reaction. This revealed that the red shift of characteristic bands at lower temperatures was mainly due to the aggregation of nanoparticles instead of larger particle size. As for the particle aggregation, it could be referred to the slow reduction of $\mathrm{Au}$ (III) ions which proceeded simultaneously with the nucleation and growth processes.

\section{Roles of wine and soda}

Fig. 8 shows the FT-IR spectrum of reaction mixture. It was observed that some characteristic peaks of acetaldehyde and ethanol appeared such as $526 \mathrm{~cm}^{-1}$ (deformation vibration of aldehyde $\mathrm{C}-\mathrm{C}=\mathrm{O}$ ), $1358 \mathrm{~cm}^{-1}$ (in-plane rocking vibration of aldehyde $\mathrm{C}-\mathrm{H}$ ), $2854 \mathrm{~cm}^{-1}$ (stretching vibration of aldehyde $\mathrm{C}-\mathrm{H}$ ), $618 \mathrm{~cm}^{-1}$ (out-of-plane deformation vibration of alcohol
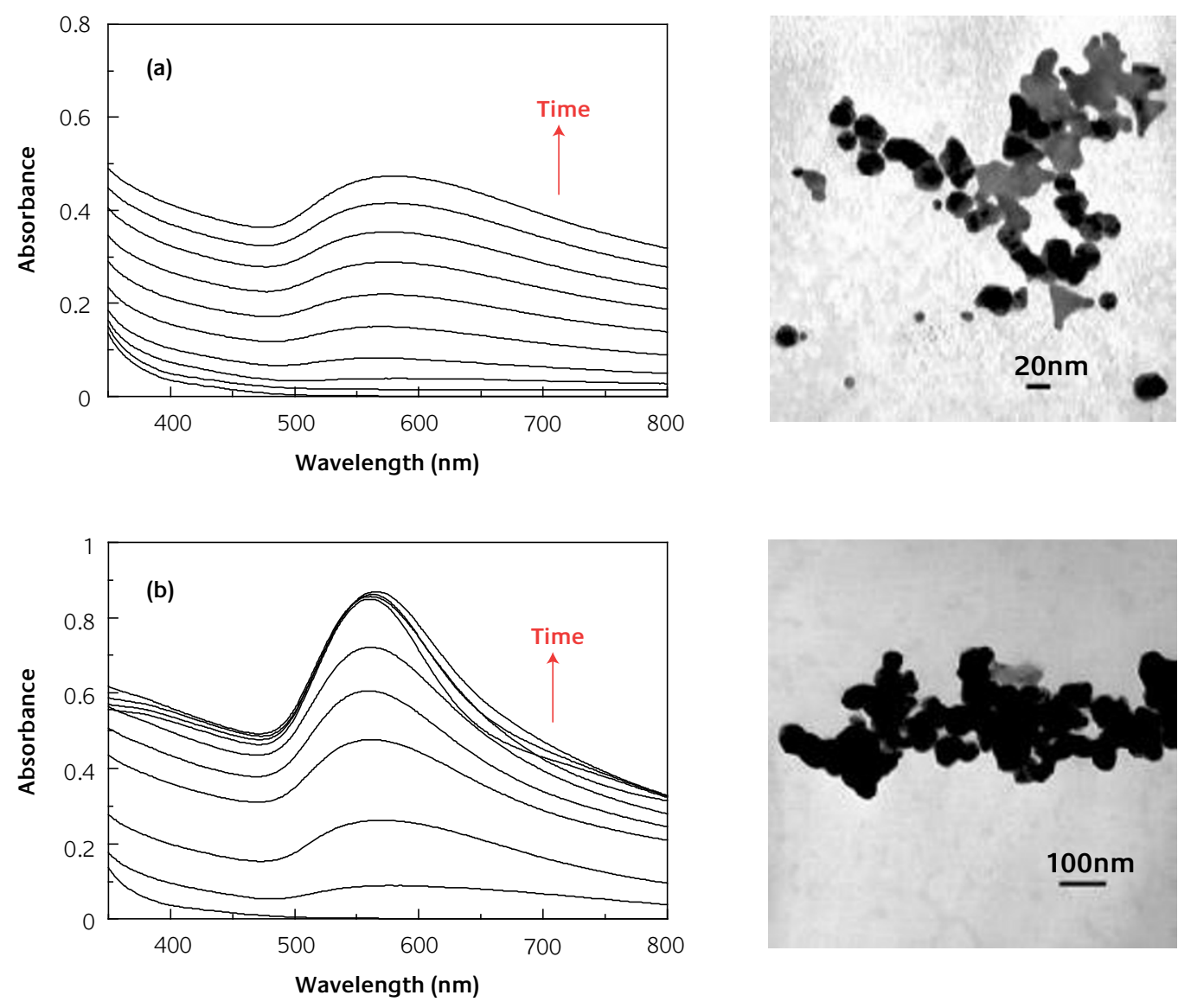

\section{Figure 7}

Time-dependent UV-VIS absorption spectra and the corresponding TEM images at a reaction time of $4 \mathrm{~h}$ for the Au nanoparticles obtained at pH 6.5 and 25 (a) and $40^{\circ} \mathrm{C}$ (b) 


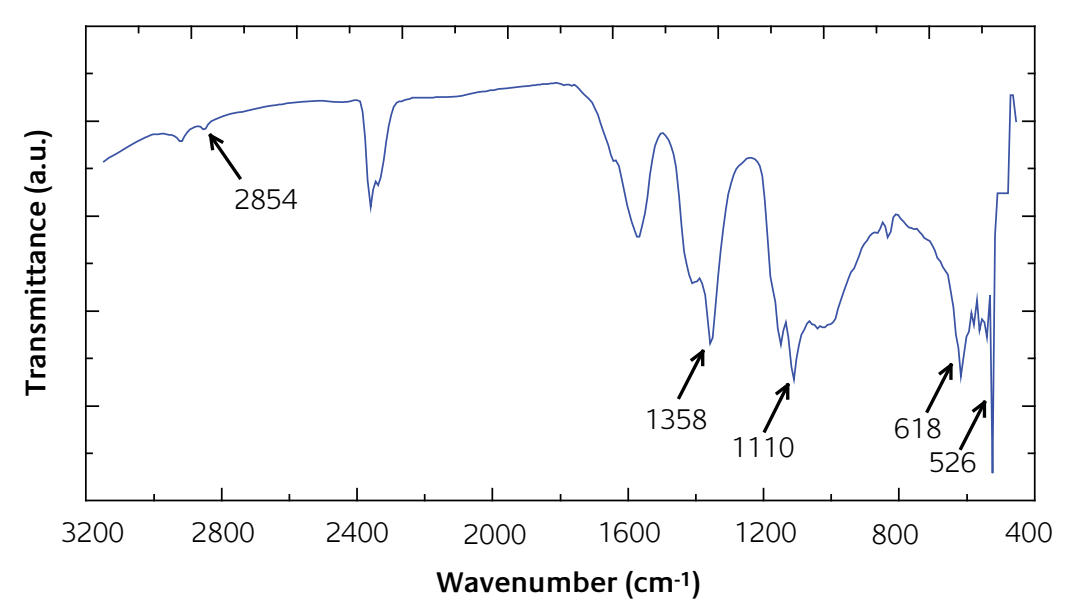

Figure 8

FT-IR spectrum of reaction mixture obtained at $55^{\circ} \mathrm{C}, \mathrm{pH} 6.5$, and a reaction time of $4 \mathrm{~h}$
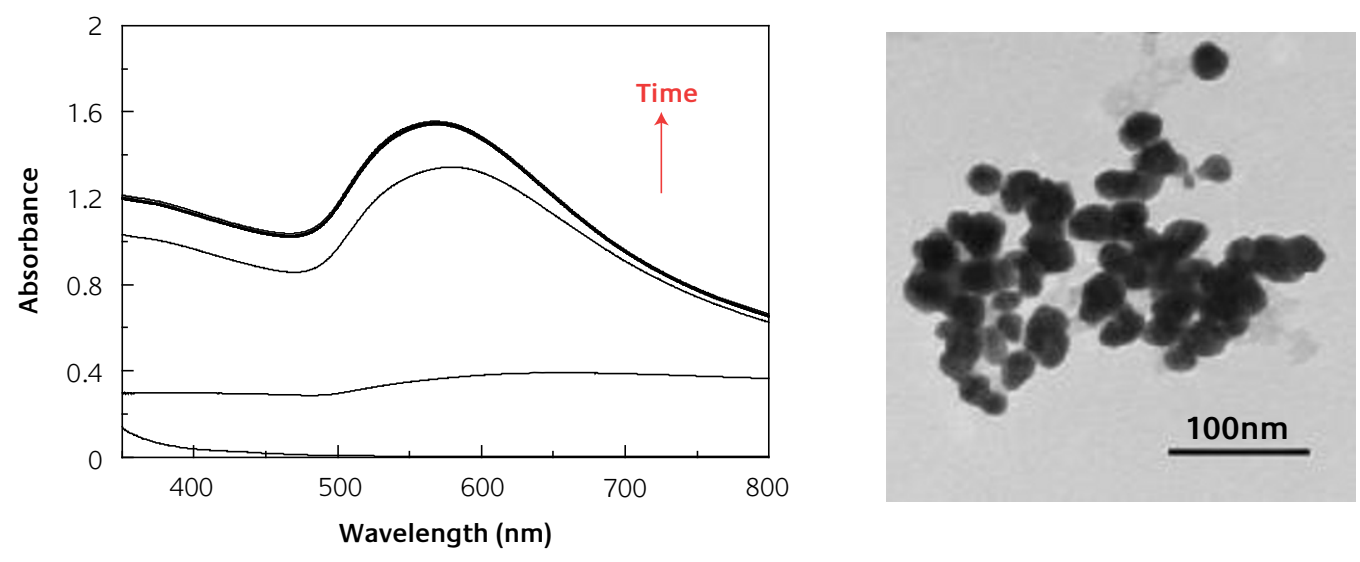

\section{Figure 9}

Time-dependent UV-VIS absorption spectra and the corresponding TEM images at a reaction time of $4 \mathrm{~h}$ for the Au nanoparticles obtained at pH 6.5 and $55^{\circ} \mathrm{C}$ when rice wine was replaced by the aqueous solution containing $40 \%$ ethanol

$\mathrm{O}-\mathrm{H}$ ), and $1110 \mathrm{~cm}^{-1}$ (stretching vibration of alcohol $\mathrm{C}-\mathrm{O}$ ). Also, some weak lattice vibrations of ions were observed such as $833 \mathrm{~cm}^{-1}, 1160 \mathrm{~cm}^{-1}\left(\mathrm{CO}_{3}{ }^{2-}\right)$, and $1420 \mathrm{~cm}^{-1}\left(\mathrm{HCO}_{3}{ }^{-}\right)$. The generation of acetaldehyde here could be attributed to the partially oxidation of the ethanol in rice wine, and revealed the formation of Au nanoparticles was achieved via the alcoholreduction route as stated above [20-21]. Furthermore, the preliminary experiment indicated that no $\mathrm{Au}$ nanoparticles were formed at $\mathrm{pH}$ 5.5-7.0 and $25-55^{\circ} \mathrm{C}$ when rice wine was replaced by water. Also, while rice wine was replaced by the aqueous solution containing $40 \%$ ethanol, similar UV-VIS absorption spectra and TEM image as observed in Figs. 2 and 3(a) were obtained at $55^{\circ} \mathrm{C}$ and $\mathrm{pH} 6.5$ (Fig. 9), revealing the formation of Au nanoparticles. So, except as a solvent, the rice wine containing $40 \%$ ethanol could be reasonably taken for a reducing agent.

Accordingly, in the absence of soda, it was found the formation rate of $\mathrm{Au}$ nanoparticles became significantly slower at $25-55^{\circ} \mathrm{C}$ (Fig. 10). Also, the formed Au nanoparticles would precipitate completely within 1 day. This implied soda not only functioned as a protective agent but also could increase the formation rate of Au nanoparticles. In fact, expect providing bicarbonate ions to form an electric double layer for the protection of Au nanoparticles, the addition of soda might result in the increase of $\mathrm{pH}$. As shown in Fig. 6, the formation rate of Au nanoparticles significantly increased with increase in $\mathrm{pH}$. Since the alcohol reduction processes of metal nanoparticles might be base-catalyzed [24], we reasonably inferred that soda also played a role of base catalyst in this work.

\section{Conclusion}

A facile and completely green route has been developed to synthesize Au nanoparticles in a solution of rice wine and soda at a slightly elevated temperature. The appropriate $\mathrm{pH}$ was around 6.5 and no extra protective agents were necessary. Interestingly, it has been known that people tried to drink solutions which contained Au nanoparticles to cure several diseases from hundreds of years ago [6]. Rice wine and soda are often used as the additives of drinks or foods, and are 

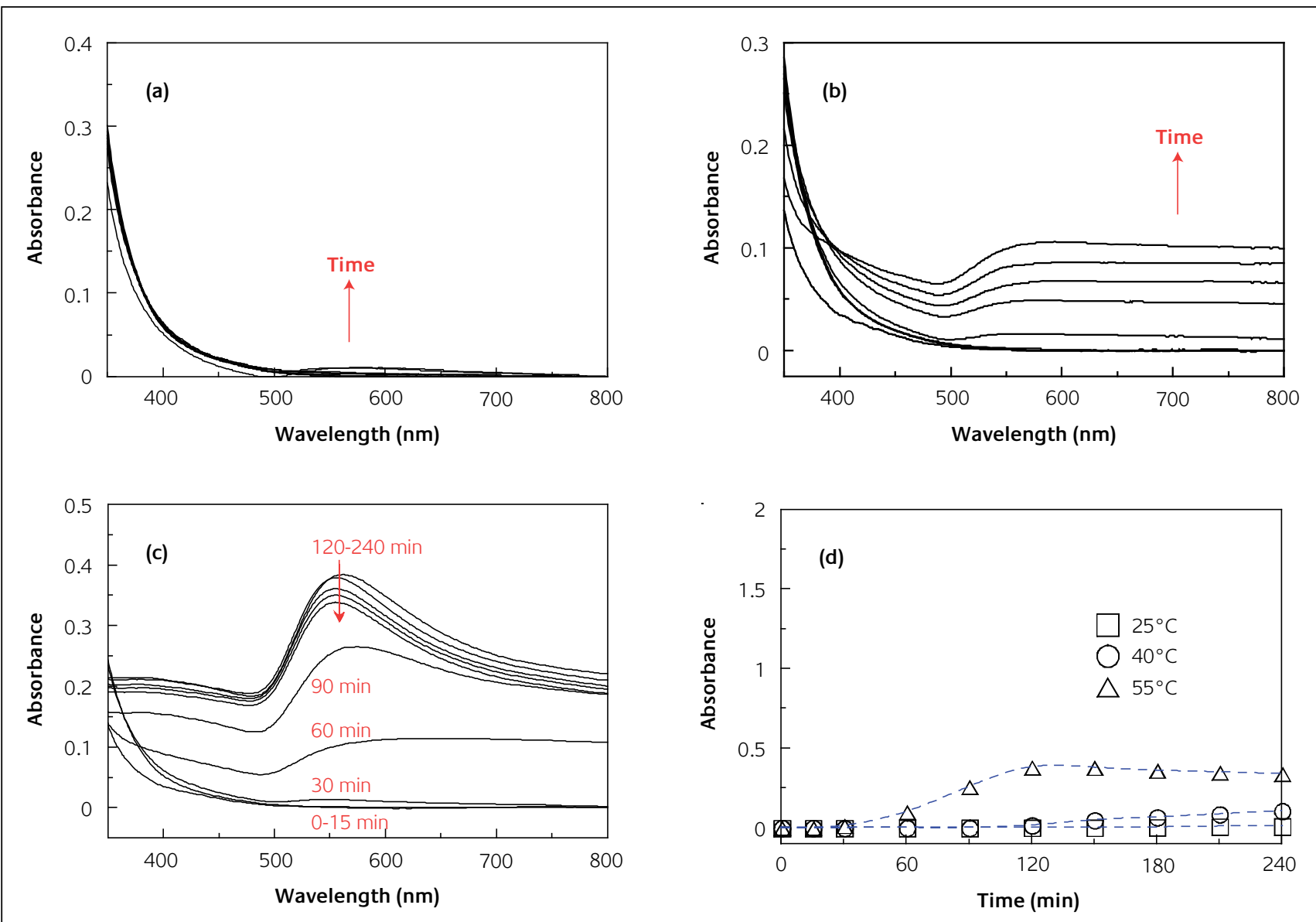

\section{Figure 10}

Time-dependent UV-VIS absorption spectra of Au nanoparticles in the absence of soda at pH 6.5 and 25 (a), 40 (b), and 55 ${ }^{\circ} \mathrm{C}(\mathrm{c})$. Fig. 10 (d) indicates the time-dependences of the absorbance at 597, 594, and 555nm for the Au nanoparticles obtained at 25, 40, and 55 $\mathrm{C}$, respectively

easily obtained in our daily life. So, by the route proposed in this work, it seems possible that people can easily make the Au nanoparticles at home. Of course, because the rice wine was used as a solvent and a reducing agent, this concept could also be extended to other alcohol drinks such as whisky, vodka, brandy etc.

The authors thank the National Science Council of the Republic of China for support (NSC 94-2214-E-006-006).

\section{About the authors}

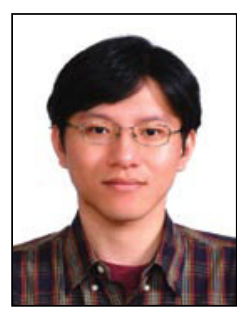

Mr. Chien-Chen Wu currently works as a PhD student in the laboratory of Prof. Chen in Department of Chemical Engineering at National Cheng Kung University (Taiwan). His research focuses on the synthesis of nano-structured materials and their applications in catalyst and electrochemistry.

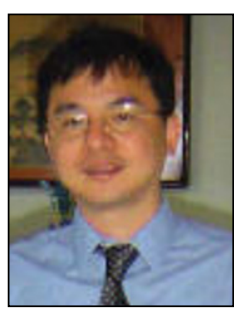

Dr. Dong-Hwang Chen is a professor of Chemical Engineering Department at National Cheng Kung University (Taiwan). His research works include the synthesis of nanoparticles, the fabrication of composite nanoparticles and thin films, the development of nanomaterials for electromagnetic wave absorption, as well as the fabrication and applications of functionalized magnetic nanocarriers in separation, catalysis, and biomedicine. 


\section{References}

M. Poliakoff, P. Anastas, Nature, 2001, 413, 257

M. Poliakoff, J.M. Fitzpatrick, T.R. Farren, P.T. Anastas, Science, 2002, 297, 807

R.A. Gross, B. Kalra, Science, 2002, 297, 803

J.M. DeSimone, Science, 2002, 297, 799

P. Raveendran, J. Fu, S.L. Wallen, J. Am. Chem. Soc., 2003, 125, 13940

M.C. Daniel, D. Astruc, Chem. Rev., 2004, 104, 293

M. Haruta, Cattech, 2002, 6, 102-115

8 M. Zayats, A.B. Kharitonov, S.P. Pogorelova, O. Lioubashevski, E. Katz, I. Willner, J. Am. Chem. Soc., 2003, 125, 16006

9 W. Jahn, J. Struct. Biol., 1999, 127, 106

10 S.A. Maier, M.L. Brongersma, P.G. Kik, S. Meltzer, A.A.G. Requicha, H.A. Atwater, Adv. Mater., 2001, 13, 1501

11 D.A. Handley, Colloidal Gold: Principles, Methods, and Applications, Hayat M. A. Ed., Academic Press: San Diego, 1989; Vol. 1, Chapter 2

12 C. Mangeney, F. Ferrage, I. Aujard, V. Marchi-Artzner, L. Lullien, O. Ouari, E.D. Rékaï, A. Laschewsky, I. Vikholm, J.W. Sadowski, J. Am. Chem. Soc., 2002, 124, 5811
13 M. Schulz-Dobrick, K.V. Sarathy, M. Jansen, J. Am. Chem. Soc., 2005, 127, 12816

14 M. Aslam, L. Fu, M. Su, K. Vijayamohanan, V. P. Dravid, J. Mater. Chem., 2004, 14, 1795

15 J. Liu, G. Qin, P. Raveendram, Y. Ikushima, Chem. Eur. J., 2006, 12, 2131

16 S. Si, R.R. Bhattacharjee, A. Banerjee, T.K. Mandal, Chem. Eur. J., 2006, 12, 1256

17 M.N. Nadagouda, R.S. Varma, Green Chem., 2006, 8, 516

18 P. Raveendran, J. Fu, S.L. Wallen, Green Chem., 2006, 8, 34

19 B. Ankamwar, C. Damle, A. Ahmad, M. Sastry, J. Nanosci. Nanotech., 2005, 5, 1665

20 H. Hirai, Y. Nakao, N. Toshima, J. Macromol. Sci. Chem., 1979, A13, 727

21 J. Chatt, B.L. Shaw, A.E. Field, J. Chem. Soc., 1964, 3466

22 K.S. Lee, M.A. El-Sayed, J. Phys. Chem. B, 2005, 109, 20331

23 J.C. Hulteen, C.J. Patrissi, D.L. Miner, E.R. Crosthwait, E.B. Oberhauser, C.R. Martin, J. Phys. Chem. B, 1997, 101, 7727

24 Z.Y. Huang, G. Mills, B. Hajek, J. Phys. Chem., 1993, 97, 11542 